\title{
Velic Coordination in French Nasals: a Real-time Magnetic Resonance Imaging Study
}

\author{
Michael Proctor ${ }^{1}$, Louis Goldstein ${ }^{2}$, Adam Lammert ${ }^{3}$ \\ Dani Byrd ${ }^{2}$, Asterios Toutios ${ }^{3}$, Shrikanth Narayanan ${ }^{2,3}$ \\ ${ }^{1}$ School of Humanities and Communications Arts, University of Western Sydney, Australia \\ ${ }^{2}$ Department of Linguistics, University of Southern California, USA \\ ${ }^{3}$ Viterbi School of Engineering, University of Southern California, USA \\ michael.proctor@uws.edu.au http://sail.usc.edu/span
}

\begin{abstract}
Production of nasal vowels in French, and nasal consonants in French and English, was examined using real-time magnetic resonance imaging (rtMRI). The coordination of velic and lingual gestures was found to be tightly controlled across different prosodic contexts in French nasals. Velum lowering in English nasal consonants did not show the same control, although the timing of the corresponding lingual gestures varied with prosodic context in the same way as for French nasals, suggesting a coordinative relationship in which oral and velic articulators are consistently phased in French nasal production. These findings illustrate the utility of real-time MRI as a method for studying velic activity and articulatory coordination in vocalic and nasal phonology.

Index Terms: speech production, velum, nasals, nasal vowels, French, articulation, real-time MRI
\end{abstract}

\section{Introduction}

The steady-state phonetic properties of nasal and nasalized vowels have been well documented [1, 2, 3, 4], and lingual articulation during nasal vowel production has also been examined using a variety of techniques $[5,6,7,8]$. Although we have a good understanding from these and other studies of the phonetic characteristics of nasalized vowels at their target postures, less is known about the coordination of oral and velic gestures in nasalized vowels.

Most kinematic data on velum activity concern nasal consonant production in languages which do not phonologically contrast oral and nasal vowels $[9,10]$. For example, it has been demonstrated that velic and labial gestures are synchronous in English syllable onset nasals, but velum lowering preceeds labial closure in coda nasal consonants $[11,12,13]$ - a coordinative pattern which is not feasible in French, where oral and nasal vowels are phonologically contrastive before nasal consonants [14].

Because French uses both consonants and vowels that contrast in nasality, it allows for the examination of the nature of compositionality in segments that coordinate oral and velic activity. If nasal vowels and nasal consonants are cognitively structured in the same way, we would expect the velum to be coordinated with its concomitant lingual gestures in the same way. Insights into articulatory coordination can be gained by examining the effects of prosodic slowing on different types of segments, depending on their position in the phrase [15]. By comparing the realization of phrase-medial and phrase-final segments in French and English, for example, we can determine whether prosodic slowing affects velic activity the same way in nasal consonants and nasal vowels.

\subsection{Studying Velic Articulation}

One reason for the lack of kinematic data on nasalization is the difficulty of obtaining reliable information about the state of the velum. Articulometry [16] and x-ray microbeam are ill-suited to nasalization studies because it is problematic to place sensors on the velum. Ultrasound cannot reliably image the velum. Videofiberscopy [17], photonasography [18] and Velotrace [10] studies are highly invasive, and x-ray and cineflurography expose subjects to unacceptable levels of radiation.

Real-time MRI is a safe, non-invasive technique that provides views of the entire midsagittal plane of the vocal tract at sufficiently high frame rates to examine articulatory coordination of lingual, labial and velic articulators $[19,20]$. Byrd et al. demonstrated the utility of the technique for examining velic coordination in English nasal consonants [11]. Delvaux et al. compared target lingual and velum postures for Belgian French vowels acquired using 5 f.p.s. real-time MRI [6], but did not investigate tongue-velum coordination. Teixeira et al. examined oral-nasal coordination in European Portuguese using real-time MRI data acquired at 14 f.p.s. [8].

\subsection{Goals}

The goal of this study is to examine the coordination of lingual and velic articulation during the production of French nasal segments in different prosodic environments. Specifically, we test two hypotheses:

i. prosodic slowing affects gestures that compose consonantal and vocalic segments in the same way;

ii. prosodic slowing is insensitive to whether a gesture is oral or velic

\section{Method}

Words contrasting nasal consonants and vowels were elicited in two prosodic contexts - phrase-medial and phrase-final - from two native speakers of French, and compared with nasal consonants produced in the same contexts by two native speakers of English. The French study participants were a 29 year old female born and raised in Montpellier (Fr1), and a 21 year old female born in Nantes and raised in Toulouse (Fr2), both native 
speakers of Standard French. The English speakers were a 41 year old Australian male from Sydney (En1, one of the authors) and a 31 year old American male from Buffalo, NY (En2, also one of the authors). Stimuli are listed in Table $1 .{ }^{1}$

\subsection{Image Acquisition}

Data were acquired using a rtMRI protocol developed specifically for the study of speech production [19]. Subjects' upper airways were imaged midsagittally with spatial resolution 68 x 68 pixels, field of view $200 \times 200 \mathrm{~mm}$, and a temporal reconstruction rate of 33.18 f.p.s. Speech was recorded inside the scanner at $20 \mathrm{kHz}$, simultaneously with the MRI acquisition, and later noise-reduced [21]. The companion video and audio recordings allow for dynamic visualization of the entire midsagittal plane of the vocal tract, including the velum and nasopharynx.

\subsection{Articulatory Analysis}

MRI data were loaded into a custom graphical user interface designed for the synchronization, inspection and analysis of companion audio and video recordings [22]. Articulatory landmarks (detailed below) in the syllables of interest were identified by examining video sequences and time-aligned audio and spectra. Frame times were recorded, from which time intervals between the articulatory events of interest were calculated. Where image transitions in the the default frame sequence were considered to be too temporally course to capture events of interest, video sub-intervals were reconstructed at higher frame rates to facilitate finer temporal resolution of articulatory details.

Time from syllable onset was measured from the frame showing maximal lip closure in the initial labial consonant $/ \mathrm{p}, \mathrm{f}, \mathrm{v} /$ beginning each target syllable (Fig. 1, left). Lingual targets in coronal consonants $/ \mathrm{t}, \mathrm{n} /$ were identified in frames showing maximal tongue tip closure in the alveolar region (Fig. 2, center). Vocalic lingual targets /a,ã,a, , ã,,$\tilde{\varepsilon} /$ were identified in frames showing maximum lowering and retraction of the tongue body in the pharyngeal region (e.g. Fig. 1, right). Timings for nasal segments $/ \mathrm{n} /, \tilde{\mathrm{V}}$ were measured with respect to the first frame showing velum lowering in the video sequence (e.g. Fig. 1, center).

\section{Results}

Articulation by subject Fr2 of the low back nasal vowel in the French word pan [pã] 'pane' is illustrated in Fig. 1. Velum lowering (frame 291) commences soon after the release of the initial labial (frame 288). By the time the tongue body achieves its target posture, the velum is fully lowered (frame 293), and remains open throughout the production of the vowel.

Production of the coda nasal consonant in the French word panne [pan] 'failure', by subject Fr2, is illustrated in Fig. 2. The velum remains raised throughout the articulation of the preconsonantal vowel (frame 201), then lowers as the tongue tip moves towards its alveolar target (frame 204).

Production of the English coda nasal consonant in the word Yvonne [i..võn] by Subject En1 is shown in Fig. 3. Like the coordination observed in the French vowel (Fig. 1), but unlike the velic activity observed during French nasal consonant production (Fig. 2), velum lowering commences soon after the release of the initial labial (frame 144), and the velum is already fully

\footnotetext{
${ }^{1}$ Tokens pet(s) and pen(s) were not elicited from subject En1.
}
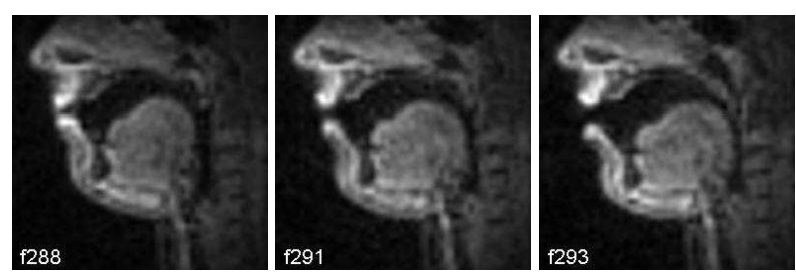

Figure 1: French nasal vowel production: pan [pã] 'pane'. Frame 288: initial labial stop; f291: tongue body retracton and initiation of velum lowering; f293: tongue body at target vowel posture, velum fully open
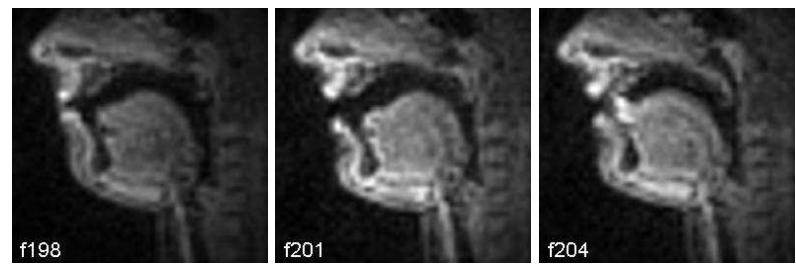

Figure 2: French coda nasal consonant production: panne [pan] 'failure'. Frame 198: initial labial stop; f201: velum remains raised during nuclear vowel; f204: velic lowering during coda alveolar nasal stop.

open by the time the tongue body achieves its target posture (frame 147) - well before the tongue tip achieves the alveolar lingual target of the coda consonant (frame 150).
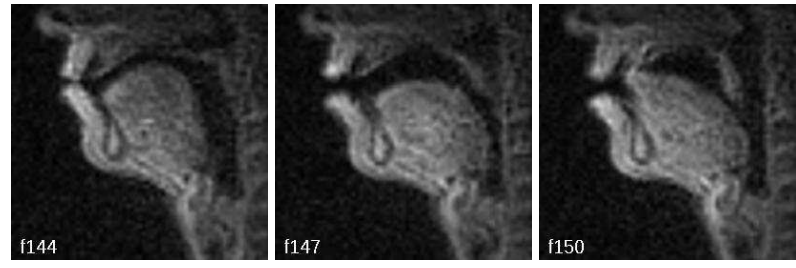

Figure 3: Coda nasal consonant production in English: Yvonne [i..võn]. Frame 144: initial labial fricative of target syllable; f147: velum fully open as tongue body achieves vowel target; f150: velum in maximally lowered position during coda alveolar nasal stop.

\subsection{Quantifying Lingual and Velic Timing}

For each utterance, six time intervals were calculated between four articulatory landmarks in the target syllable, using the criteria described in §2.2: (i) onset to vocalic target (V); (ii) onset to initiation of velic lowering (Vel), (iii) onset to tongue tip closure (TT); (iv) vocalic target to initiation of velic lowering; (v) vocalic target to tongue tip closure; and (vi) initiation of velic lowering to tongue tip closure. Mean durations of each interval are compared in phrase-medial (control) and phrase final (boundary-lengthened) position for both languages in Table 2.

\subsection{Lingual and Velic Coordination}

In the eight French words containing nasal vowels examined in this study, velum lowering commenced an average of 16 msec (subject $\mathrm{Fr} 1)$ and $58 \mathrm{msec}(\mathrm{Fr} 2)$ before the tongue body achieved its vocalic target, when the lexical target was uttered 


\begin{tabular}{|c|c|c|c|c|c|c|}
\hline \multirow{2}{*}{\multicolumn{2}{|c|}{ NO VELUM LOWERING }} & \multicolumn{2}{|c|}{ FRENCH } & & \multicolumn{2}{|c|}{ ENGLISH } \\
\hline & & BOUNDARY & PHRASE MEDIAL & & BOUNDARY & PHRASE MEDIAL \\
\hline \multirow[t]{4}{*}{ i. } & [at] & Voici un nouveau pâte & Voici un nouveau pâte aussi & [at] & I like the pot & I like the pot as well \\
\hline & [at] & Voici une nouvelle batte & Voici une nouvelle batte aussi & {$[\Lambda \mathbf{t}]$} & I like the butt & I like the butt as well \\
\hline & {$[\mathrm{et}]$} & Voici une nouvelle bête & Voici une nouvelle bête aussi & {$[\varepsilon t]$} & I like the pet & I like the pet as well \\
\hline & {$[\varepsilon \mathbf{t}]$} & Voici une nouvelle fête & Voici une nouvelle fête aussi & {$[\varepsilon t]$} & I like the bet & I like the bet as well \\
\hline \multirow[t]{4}{*}{ ii. } & [.to $]$ & Voici un nouveau bateau & Voici un nouveau bateau aussi & [ats] & I like the pots & I like the pots as well \\
\hline & {$[. t o]$} & Voici un nouveau veto & Voici un nouveau veto aussi & {$[\Lambda \mathrm{ts}]$} & I like the butts & I like the butts as well \\
\hline & [.te] & Voici un nouveau pâté & Voici un nouveau pâté aussi & {$[\varepsilon \mathbf{t s}]$} & I like the pets & I like the pets as well \\
\hline & {$[. t y]$} & Voici un nouveau fétu & Voici un nouveau fétu aussi & [ets] & I like the bets & I like the bets as well \\
\hline \multicolumn{7}{|c|}{ C-VELUM LOWERING } \\
\hline \multirow[t]{4}{*}{ i. } & {$[\mathrm{an}]$} & Voici un nouvelle panne & Voici un nouvelle panne aussi & {$[\mathrm{an}]$} & I like Yvonne & I like Yvonne as well \\
\hline & {$[\mathrm{an}]$} & Voici un nouveau fan & Voici un nouveau fan aussi & {$[\Lambda \mathbf{n}]$} & I like the bun & I like the bun as well \\
\hline & {$[\varepsilon \mathbf{n}]$} & Voici un nouveau pêne & Voici un nouveau pêne aussi & {$[\varepsilon \mathbf{n}]$} & I like the pen & I like the pen as well \\
\hline & {$[\varepsilon \mathbf{n}]$} & Voici une nouvelle benne & Voici une nouvelle benne aussi & {$[\varepsilon \mathbf{n}]$} & I like the fen & I like the fen as well \\
\hline \multirow[t]{4}{*}{ ii. } & {$[. n o]$} & Voici un nouveau panneau & Voici un nouveau panneau aussi & [ant] & I like the font & I like the font as well \\
\hline & {$[. n o]$} & Voici un nouveau vanneau & Voici un nouveau panneau aussi & {$[\Lambda \mathbf{n t}]$} & I like the buns & I like the buns as well \\
\hline & {$[. \mathbf{n} \varepsilon]$} & Voici un nouveau benêt & Voici un nouveau benêt aussi & {$[\mathrm{ent}]$} & I like the pens & I like the pens as well \\
\hline & {$[. n y]$} & Voici un nouveau venu & Voici un nouveau venu aussi & [ent] & I like the fens & I like the fens as well \\
\hline \multicolumn{7}{|c|}{ V-VELUM LOWERING } \\
\hline \multirow[t]{4}{*}{ i. } & {$[\tilde{\mathbf{a}}]$} & Voici un nouveau pan & Voici un nouveau pan aussi & & & \\
\hline & {$[\tilde{\mathbf{a}}]$} & Voici un nouveau ban & Voici un nouveau ban aussi & & & \\
\hline & {$[\tilde{\boldsymbol{\varepsilon}}]$} & Voici un nouveau sapin & Voici un nouveau sapin aussi & & & \\
\hline & {$[\tilde{\boldsymbol{\varepsilon}}]$} & Voici un nouveau copain & Voici un nouveau copain aussi & & & \\
\hline \multirow[t]{4}{*}{ ii. } & [ãt] & Voici une nouvelle pente & Voici une nouvelle pente aussi & & & \\
\hline & [ãt] & Voici une nouvelle vente & Voici une nouvelle vente aussi & & & \\
\hline & {$[\tilde{\boldsymbol{\varepsilon}} \mathrm{s}]$} & Voici une nouvelle pince & Voici une nouvelle pince aussi & & & \\
\hline & {$[\tilde{\boldsymbol{\varepsilon}} \mathrm{t}]$} & Voici une nouvelle feinte & Voici une nouvelle feinte aussi & & & \\
\hline
\end{tabular}

Table 1: Stimuli used in rtMRI experiment. Nasal segments elicited in labial-initial words to provide a common articulatory landmark at syllable onset. Nasal segments compared with coronal non-nasals in (i) word-final position, and (ii) one segment removed from the word edge. All words elicited in both phrase-final and phrase-medial (control) environments.

phrase-medially (Table 2). ${ }^{2}$

In the eight French words containing coda nasal consonants elicited here, velum lowering commenced on average 53 msec (subject Fr1) and $51 \mathrm{msec}(\mathrm{Fr} 2)$ before the tongue tip achieved alveolar closure, when the lexical target was uttered phrase-medially (Table 2). Nasalization commenced an average of $22 \mathrm{msec}(\mathrm{Fr} 1)$ and $32 \mathrm{msec}(\mathrm{Fr} 2)$ after the tongue body had achieved its pre-consonantal vocalic target. In none of the French words examined in this study did the velum lowering associated with a nasal coda consonant commence before the tongue body achieved the target posture for the tautosyllabic vowel, although initiation of velum lowering was synchronous with vowel target achivement in the phrase-medial utterance benne by Subject Fr1.

\subsection{Velic Articulation and the Influence of Prosody}

To quantify the effect of prosodic context on gestural timing, the difference between phrase-final and phrase-medial (control) durations was calculated for each interval. Mean duration differences between both prosodic contexts, calculated across all comparable utterances by both speakers of each langugage, are shown in Table 3.

In both French and English, syllable duration (time from onset to the final gesture) is lengthened at phrase boundaries. Timings are consistent with the hypothesis that lengthening is progressive as the boundary is approached: in both lan-

\footnotetext{
${ }^{2}$ The word fan was produced [fã] by subject Fr1, and [fan] by subject Fr2; the word ban was produced [bã] by subject Fr1, and [ban] by subject Fr2.
}

\begin{tabular}{lrrrrrrr}
\hline & \multicolumn{2}{c}{ TIME FrOM ONSET } & \multicolumn{2}{c}{ FROM VOWEL } & TT \\
FRENCH & $\rightarrow \mathrm{V}$ & $\rightarrow$ Vel & $\rightarrow$ TT & $\rightarrow$ Vel & $\rightarrow$ TT & $\rightarrow$ Vel \\
\hline Control & 22 & - & 30 & - & 8 & - \\
C-velum & 32 & 34 & 43 & 2 & 11 & 9 \\
V-velum & 40 & 3 & - & -37 & - & - \\
\hline ENGLISH & & & & & & \\
Control & 35 & - & 63 & - & 28 & - \\
C-velum & 17 & -18 & 59 & -35 & 43 & 77 \\
\hline
\end{tabular}

Table 3: Boundary Lengthening in French Nasal Syllables. Additional duration (msec) between articulatory landmarks in phrase-final syllables, compared to phrase-medial (control) mean durations (Table 2).

guages, intervals from syllable onset to coda consonant TT target lengthens more than the interval from syllable onset to $\mathrm{V}$ target. (Alternatively, this could indicate that lengthening is proportional to duration).

Overall, and for subject Fr1, these data suggest that the effect of prosodic boundaries on velum gesture timing in French may be the same regardless of whether the nasalization is associated with a vowel or a consonant, as predicted by compositionally. In both types of segment, mean initiation of velic activity is delayed with respect to the onset (Table 3 ), and the mean time by which it precedes the gesture to which it is associated increases modestly at a phrase boundary for both nasal vowels $(37 \mathrm{~ms}$ ) and nasal consonants $(9 \mathrm{~ms})$. However, for subject $\mathrm{Fr} 2$, unlike $\mathrm{Fr} 1$, no change in the coordination of tongue-tip and velum lowering gestures was observed in phrase-final, com- 


\begin{tabular}{|c|c|c|c|c|c|c|c|c|c|c|c|c|}
\hline \multirow[b]{3}{*}{ FRENCH: FR1 } & \multicolumn{6}{|c|}{ PHRASE-MEDIAL } & \multicolumn{6}{|c|}{ PHRASE-FINAL } \\
\hline & \multirow{2}{*}{$\begin{array}{l}\text { TIMH } \\
\rightarrow \mathrm{V}\end{array}$} & \multicolumn{2}{|c|}{ FROM ONSET } & \multicolumn{2}{|c|}{ FROM VOWEL } & \multirow{2}{*}{$\begin{array}{r}\text { VEL } \\
\rightarrow \text { TT }\end{array}$} & \multirow{2}{*}{$\begin{array}{l}\text { TIMH } \\
\rightarrow \mathrm{V}\end{array}$} & \multirow{2}{*}{\multicolumn{2}{|c|}{$\begin{array}{l}\text { FROM ONSET } \\
\rightarrow \mathrm{Vel} \rightarrow \mathrm{TT}\end{array}$}} & \multicolumn{2}{|c|}{ FROM VOWEL } & \multirow{2}{*}{$\begin{array}{r}\text { VEL } \\
\rightarrow \text { TT }\end{array}$} \\
\hline & & $\rightarrow$ Vel & $\rightarrow \mathrm{TT}$ & $\rightarrow \mathrm{Vel}$ & $\rightarrow \mathrm{TT}$ & & & & $\rightarrow \mathrm{TT}$ & $\rightarrow$ Vel & $\rightarrow \mathrm{TT}$ & \\
\hline No velum lowering (control) & 48 & - & 130 & - & 82 & - & 75 & - & 167 & - & 91 & - \\
\hline C-velum lowering & 56 & 75 & 128 & 19 & 71 & 53 & 100 & 123 & 188 & 23 & 88 & 66 \\
\hline V-velum lowering & 84 & 68 & - & -16 & - & - & 153 & 81 & - & -72 & - & - \\
\hline \multicolumn{13}{|l|}{ FRENCH: FR2 } \\
\hline No velum lowering (control) & 76 & - & 159 & - & 83 & - & 93 & - & 183 & - & 90 & - \\
\hline $\mathrm{C}$-velum lowering & 89 & 127 & 177 & 38 & 88 & 51 & 103 & 148 & 199 & 44 & 96 & 51 \\
\hline V-velum lowering & 123 & 73 & - & -50 & - & - & 134 & 66 & - & -68 & - & - \\
\hline \multicolumn{13}{|l|}{ ENGLISH: EN1 } \\
\hline No velum lowering(control) & 125 & - & 255 & - & 130 & - & 170 & - & 330 & - & 160 & - \\
\hline $\mathrm{C}$-velum lowering & 120 & 100 & 230 & -20 & 110 & 130 & 125 & 60 & 295 & -65 & 170 & 235 \\
\hline \multicolumn{13}{|l|}{ ENGLISH: EN2 } \\
\hline No velum lowering(control) & 111 & - & 220 & - & 108 & - & 137 & - & 271 & - & 134 & - \\
\hline $\mathrm{C}$-velum lowering & 112 & 75 & 242 & -37 & 131 & 167 & 141 & 80 & 296 & -61 & 156 & 217 \\
\hline
\end{tabular}

Table 2: Articulatory Timing in French (Top) and English (Bottom) Nasals: Phrase-Medial vs. Phrase-Final Syllables. Mean time intervals (msec) between four articulatory landmarks: maximum labial closure in onset consonant, achievement of vocalic tongue body target (V), onset of velic lowering (Vel), and achievement of tongue tip closure (TT).

pared to phrase-medial elicitation conditions.

\section{Discussion}

As expected, velic articulation is timed differently in French nasal vowels and nasal consonants. Initiation of velum lowering appears to precede target achievement of the gesture to which it is coordinated by a similar interval of time, regardless of whether that gesture is $\mathrm{C}$ or V. For example, in the phrasefinal condition, velum lowering precedes the vowel target by an average interval of 51 to $66 \mathrm{~ms}$ in words containing nasal vowels and precedes the coda consonant target by mean intervals of 68 to $72 \mathrm{msec}$ in words containing nasal consonants. In English, the pattern of velic timing in coda nasal consonants is more like that observed in French nasal vowels in that velum lowering precedes achievement of the tautosyllabic vowel target; unlike in any French type of nasal segment, this results in tongue-velum coordination patterns spread over a much larger part of the syllable in English, and C-Velum durations up to five times larger than any observed in French (Table 2).

These data indicate that French nasal segments may be produced with two different timings of velic activity for utterances with nasal vowels vs. nasal coda consonants. However, consistent with a compositional, coupling-graph view of coordination [23], the timing between the velic gesture and the oral constriction gesture to which it is predicted to be coupled appears to be relatively consistent, regardless of whether that gesture is consonantal or vocalic, and that, at least in the case of segments occuring in the syllable rime, slowing of the velic gesture due to a prosodic boundary affects both consonantal and vocalic nasal segments. The results of this preliminary investigation are consistent with a model in which velic gestures in French are consistently coordinated, and therefore uniformly affected by pi-gestures [15], although more data are required to examine exactly how these patterns of coordination differ between individuals $[24,16,25]$, lexical items, and location in the syllable.

In English, the pattern of coordination exhibited by the velum gesture in coda nasals resembles that observed in the nasal vowel case in French, in that it preceeds achivement of the tautosyllabic tongue body gesture. This is consistent with patterns of nasal coordination previously observed in English $[12,26,13,11]$, and the hypothesized coupling graph in Goldstein, et al. (2006) [23]. The results across the phase boundary variation also support the hypothesis that velic gesture is being coordinated with respect to the vowel - it maintains its relation to the vowel as slowing occurs, as much as it does for the nasal vowels in French. However, when we look at how the velic gesture is coordinated with respect to the coda TT gesture, it shows marked changes as a function of boundary, preceding the TT gesture by $77 \mathrm{~ms}$ more at phrase boundary than phraseinternally. This variability in oral-velic coordination as a function of boundary strength resembles patterns observed in other multi-gestural segments, such as tongue tip-tongue dorsum coordination in English coda laterals [27].

It remains to be seen whether these other cases can also be profitably examined in terms of timing with respect to vowel, rather than coda consonant. In general, it is not yet known how these patterns of coordination vary across segments in different languages, and how they are influenced by prosodic gestures at higher levels of phonological organization. One interesting difference between French and English is that the interval from the onset consonant target to vowel target does not appear to lengthen much in English, particularly in the word with the final nasal. This may suggest that the scope of lengthening is more restricted in English, or that the coordination of the pi-gesture with the constriction gestures is different in English and French. More data are required to examine these issues further.

\section{Conclusions}

The results of this study provide further insights into the mechanisms of production of nasal vowels and consonants in French, and inter-articulator coordination in nasal segments in general. The data suggest that velic articulation is consistently coordinated with oral articulation during the production of nasal segments in French. The patterning of velic gestures for final nasal consonants in English appears to be similar to the pattern for French nasal vowels, as was suggested by earlier research. These data further illustrate the importance of real-time MRI as a method for studying velic activity and articulatory coordination in nasalization studies.

\section{Acknowledgements}

Research supported by NIH Grants R01 DC007124-01 and R01 DC03172. 


\section{References}

[1] P. Delattre, "La nasalite vocalique en francais et en anglais," French Review, vol. 39, pp. 92-109, 1955.

[2] S. Hawkins and K. N. Stevens, "Acoustic and perceptual correlates of the non-nasal/nasal distinction for vowels," $J A S A$, vol. 77, no. 4, pp. 1560-1575, 1985.

[3] S. Maeda, "Acoustics of vowel nasalization and articulatory shifts in french nasal vowels," in Nasals, Nasalization, and the Velum, M. K. Huffman and R. A. Krakow, Eds. San Diego: Academic Press, 1993, pp. 147-170.

[4] M. Y. Chen, "Acoustic correlates of english and french nasalized vowels," JASA, vol. 102, no. 4, pp. 2360-2370, 1997.

[5] A. Bothorel, P. Simon, F. Wioland, and J. Zerling, "Cinéradiographie des voyelles et consonnes du français," Travaux de l'IPS, vol. 18, p. 1296, 1986.

[6] V. Delvaux, T. Metens, and A. Soquet, "French nasal vowels: acoustic and articulatory properties," in Proc. ICSLP, Denver, Co., Sept. 16-20 2002, pp. 53-56.

[7] R. Shosted, C. Carignan, and P. Rong, "Managing the distinctiveness of phonemic nasal vowels: Articulatory evidence from hindi," JASA, vol. 131, no. 1, pp. 455-465, 2012.

[8] A. Teixeira, P. Martins, C. Oliveira, C. Ferreira, A. Silva, and R. Shosted, "Real-time mri for portuguese," in Computational Processing of the Portuguese Language, H. C. et al., Ed. Berlin: Springer, 2012, pp. 306-317.

[9] F. Bell-Berti, T. Baer, K. Harris, and N. S., "Coarticulatory effects of vowel quality on velar function," Phonetica, vol. 36, pp. 187-193, 1979.

[10] S. Horiguchi and B.-B. F., "The velotrace: a device for monitoring velar position,” J. Cleft Palate, vol. 2, pp. 104 111, 1987.

[11] D. Byrd, S. Tobin, E. Bresch, and S. Narayanan, "Timing effects of syllable structure and stress on nasals: a realtime MRI examination," J. Phon., vol. 37, pp. 97-110, 2009.

[12] K. L. Moll and R. G. Daniloff, "Investigation of the timing of velar movements during speech," JASA, vol. 50, pp. 678-684, 1971.

[13] R. A. Krakow, "Nonsegmental influences on velum movement patterns: Syllables, sentences, stress, and speaking rate," in Nasals, Nasalization, and the Velum, M. K. Huffman and R. A. Krakow, Eds. San Diego: Academic Press, 1993, p. 87116.

[14] A. Cohn, "Phonetic and phonological rules of nasalization," Ph.D. dissertation, University of California, Los Angeles, 1990.

[15] D. Byrd and E. Saltzman, "The elastic phrase: Dynamics of boundary-adjacent lengthening," J. Phon., vol. 31, pp. 149-180, 2003.

[16] S. Rossato, P. Badin, and F. Bouaouni, "Velar movements in French: an articulatory and acoustical analysis of coarticulation," in Proc. Intl. Congress of Phonetic Sciences, Barcelona, Spain, 2003, pp. 3141-3144.

[17] A. Amelot, "Étude aérodynamique, fibroscopique, acoustique et perceptive des voyelles nasales du français." $\mathrm{Ph} . \mathrm{D}$. dissertation, Paris: Université Paris III, Sorbonne Nouvelle, 2004.

[18] J. J. Ohala, "Monitoring soft-palate movements in speech," JASA, vol. 50, p. 140, 1971.
[19] S. Narayanan, K. Nayak, S. Lee, A. Sethy, and D. Byrd, "An approach to real-time magnetic resonance imaging for speech production," JASA, vol. 115, no. 4, pp. 17711776, 2004.

[20] E. Bresch, Y.-C. Kim, K. Nayak, D. Byrd, and S. Narayanan, "Seeing speech: Capturing vocal tract shaping using real-time MRI [Exploratory DSP]," IEEE Signal Process. Mag., vol. 25, no. 3, pp. 123-132, May 2008.

[21] E. Bresch, J. Nielsen, K. Nayak, and S. Narayanan, "Synchronized and noise-robust audio recordings during realtime MRI scans," JASA, vol. 120, no. 4, pp. 1791-1794, 2006.

[22] S. Narayanan, E. Bresch, P. K. Ghosh, L. Goldstein, A. Katsamanis, Y.-C. Kim, A. Lammert, M. I. Proctor, V. Ramanarayanan, and Y. Zhu, "A multimodal real-time MRI articulatory corpus for speech research," in Proc. Interspeech, Florence, Italy, Aug 2011.

[23] L. Goldstein, D. Byrd, and E. Saltzman, "The role of vocal tract gestural action units in understanding the evolution of phonology," in Action to Language via the Mirror Neuron System, M. Arbib, Ed. Cambridge University Press, 2006, pp. 215-249.

[24] S. Rossato, "Du son au geste, inversion de la parole: le cas des voyelles nasales," Ph.D. dissertation, Signal Image Parole Télécoms, Institut National Polytechnique de Grenoble, 2000

[25] O. Engwall, V. Delvaux, and T. Metens, "Interspeaker variation in the articulation of nasal vowels," in Proc. ISSP, 2006, pp. 3-10.

[26] J. Vaissière, "Prediction of velum movement from phonological specification," Phonetica, vol. 45, pp. 122-139, 1988.

[27] R. Sproat and O. Fujimura, "Allophonic variation in English $/ 1 /$ and its implications for phonetic implementation," J. Phon., vol. 21, no. 3, pp. 291-311, 1993. 